\title{
Dynamic comfort inside the building during pedestrian traffic
}

\author{
Oleg Mkrtychev ${ }^{1, *}$ \\ ${ }^{1}$ Moscow State University of Civil Engineering, Yaroslavskoe shosse, 26, Moscow, 129337, Russia
}

\begin{abstract}
Dynamic comfort of people inside buildings and structures has been studied in the works of $[1,2]$, but these works cover only industrial, manufacturing, and sports facilities. Currently, public (exhibition centers, shopping malls, etc.) and residential buildings and structures are challenged with providing dynamic comfort as well. This is due to the possibility of using high-strength and lightweight materials in construction, making the building more sensitive to dynamic effects.

The main purpose of the dynamic comfort analysis is to remove vibrations or reduce such vibrations to an acceptable level stipulated in the regulations.

A source of vibrations can be external (underground and surface transport, construction work, etc.) and internal (equipment at factories, workshops, etc.). One of the internal factors are dynamic vibrations from pedestrian traffic.
\end{abstract}

Among many harmful and dangerous factors affecting a person, there are those which a person encounters daily. Vibration is one of these factors. Vibration exposure in residential and public buildings and facilities has a significant impact on the comfort of people and affects their emotional well-being.

The conditions aimed at ensuring dynamic comfort are regulated through establishing specific loads, limiting deflections or thresholds of natural frequencies of a facility [2].

To obtain the correct results and assess them, it is necessary to apply appropriate calculation methods and techniques. Currently, design standards do not include specific guidelines and recommendations for the design of buildings and structures subjected to dynamic impact from pedestrian traffic and for the assessment of dynamic comfort.

In this study we review the example of an exhibition center (Figure 1) to consider major elements of the analysis of dynamic comfort of pedestrians inside the building:

- run a structural analysis of the building by the second limit state and check for the compliance with vibration-related health standards for the design of buildings and structures;

- compare the results of design calculations for facilities by dynamic impact through explicit and implicit schemes of integration of motion equations.

* Corresponding author: marina8busalova@gmail.com 


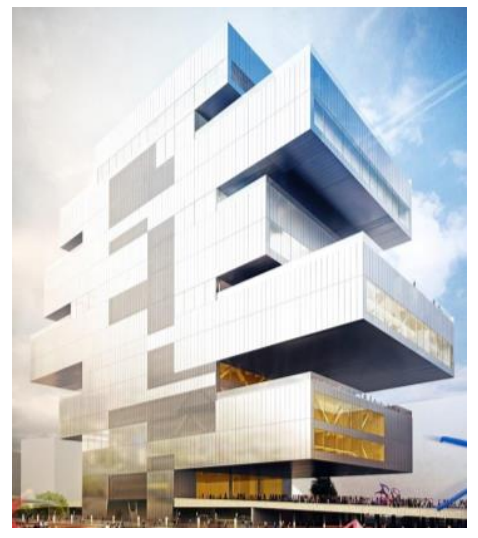

Fig. 1. Building of the exhibition center.

A spatial design finite element model was applied to design the building. We performed calculations considering geometric and physical nonlinearities in the dynamic setting. The finite element model of the building and the longest console section are shown in Figure 2.

a)

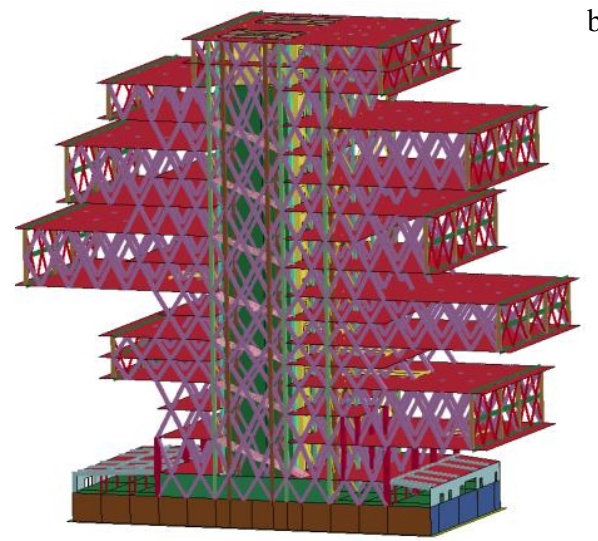

b)

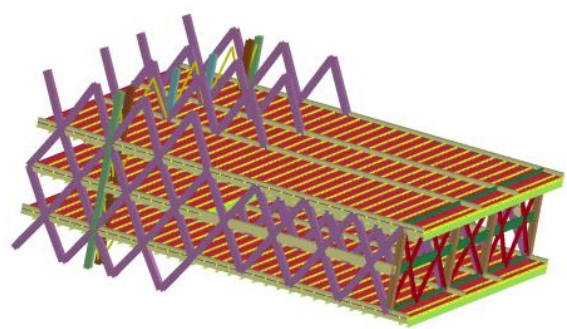

Fig. 2. Finite element model. a) general view; b) console section.

The basic design solutions of the facility are described in Table 1.

Table 1. The basic design solutions of the facility.

\begin{tabular}{|l|l|}
\hline Structural layout of the building & Frame-braced \\
\hline Dimensions in plan, $\mathrm{m}$ & $126 \times 45,6$ \\
\hline Number of floors & 18 \\
\hline Length of the longest console section, $\mathrm{m}$ & 35,1 \\
\hline $\begin{array}{l}\text { Compression strength class of concrete for walls, } \\
\text { cores, and slabs }\end{array}$ & $\mathrm{B} 60$ \\
\hline Grade of steel for elements of the main frame & $\mathrm{C} 440$ \\
\hline Grade of steel for beams & $\mathrm{C} 345$ \\
\hline
\end{tabular}


Dynamic comfort during pedestrian traffic inside the building is tested by calculations for a special combination of loads and impacts, which includes all permanent loads, as well as an appropriate dynamic effect. Load reliability factors, load combination factors, and a reliability factor for building criticality are assumed equal to one.

Permanent loads are set to:

- Weight - in accordance with the density of materials (for steel $-7,850 \mathrm{~kg} / \mathrm{m}^{3}$; for concrete structures $-2,500 \mathrm{~kg} / \mathrm{m}^{3}$ );

- Load from the weight of the flooring on the beam and roof on the cover $-5,474$ $\mathrm{kH} / \mathrm{m}^{2}$.

The dynamic impact of a person or a group of people on the building can be represented as a time-dependent force or a set of forces in the places of their application. In accordance with [3-6], the load, arising from the walk of a person, is described by the following formula:

$$
\frac{F_{z}(t)}{G}=1+\sum_{k=1}^{n} c_{k} \sin \left(2 \pi k f_{s} t+\varphi_{k}\right)
$$

, where $G$ is the weight of a person, $c_{k}$ - the amplitude of the $k$-harmonics $\left(c_{1}=0,37 \cdot\left(f_{s}-1\right), \varphi_{k}-\right.$ the initial phase of the $k$-harmonics, $f_{s}$ - the frequency of steps.

The example of the initial dynamic impact on the building of a walking person is given in Figure 3.

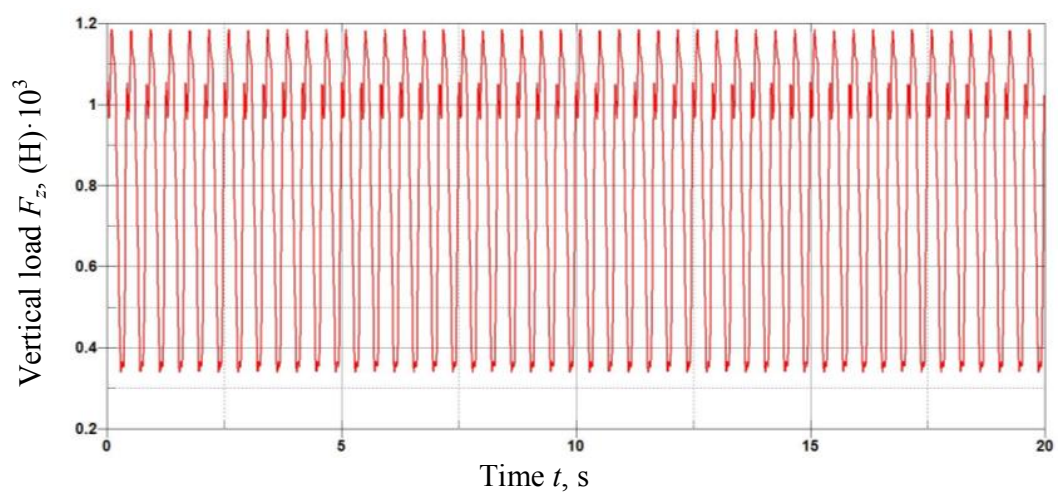

Fig. 3. Impact of one person walking.

The damping effect is an important property, determining the level of vibration near the source and their nature. The calculated damping for steel structures is assumed to be $1 \%$ of critical damping, which corresponds to the value of the inelastic resistance factor $\gamma=0,03$ and the logarithmic decrement of vibrations $\delta=0,08$.

The calculations for the building were performed on LS-DYNA PC. We used both explicit and implicit schemes of integration for motion equations. To further analyze the results, we determined basic parameters of vibrations, which included velocity and acceleration in the corresponding frequency range.

Figure 4 shows diagrams of the response of a console of the building to dynamic impact of pedestrians. 
a)

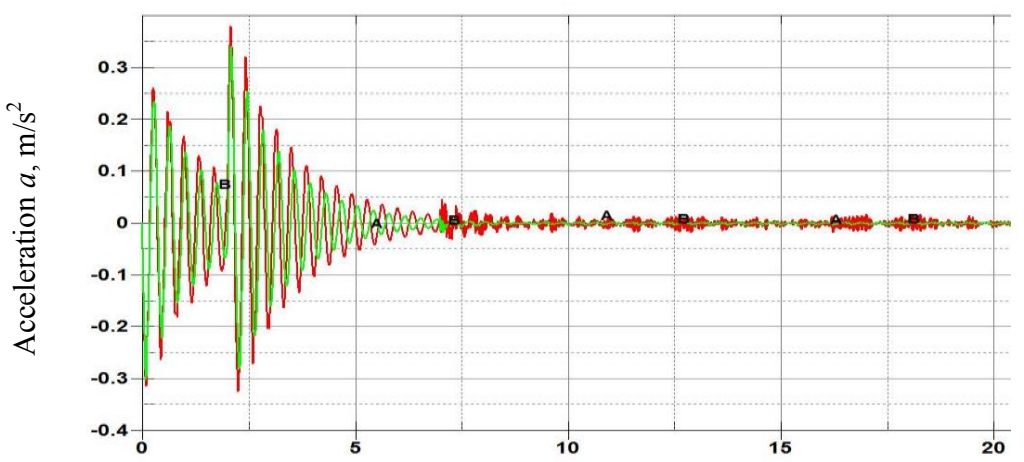

b)

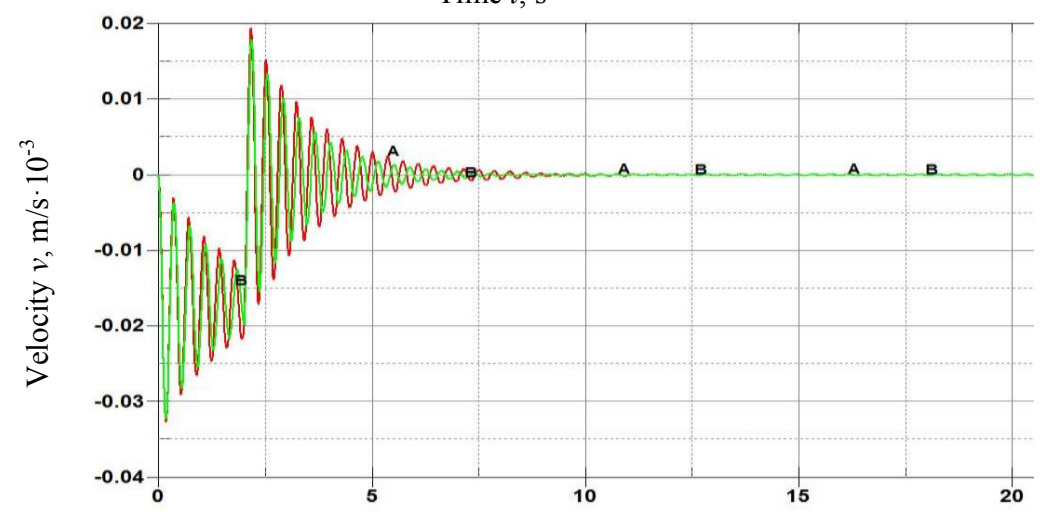

Time $t, \mathrm{~s}$

A — implicit scheme (red line); B - explicit scheme (green line)

Fig. 4. Graphs of a) acceleration and b) velocity at the grid point.

Below are the diagrams of the response of a console of the building to the impact of pedestrian traffic in the zone of steady vibrations (Figure 5).

a)

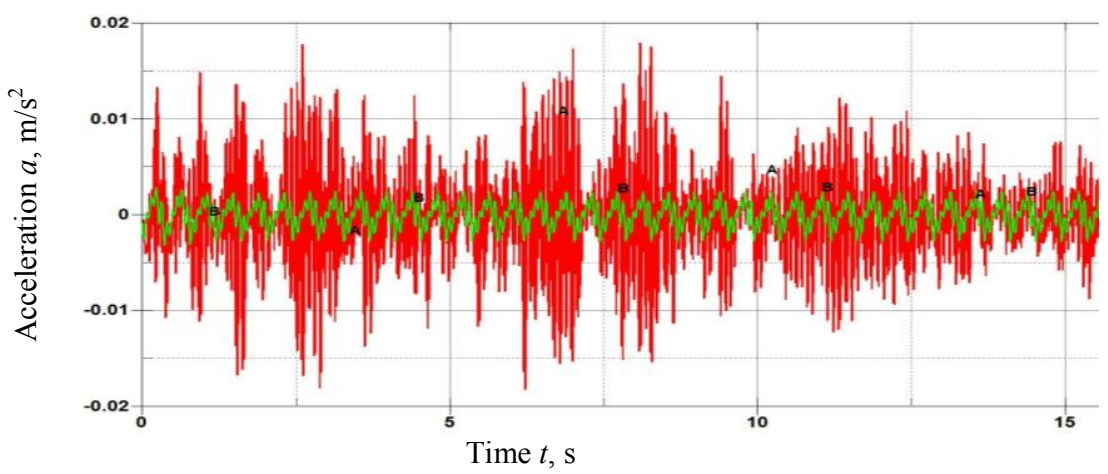


b)

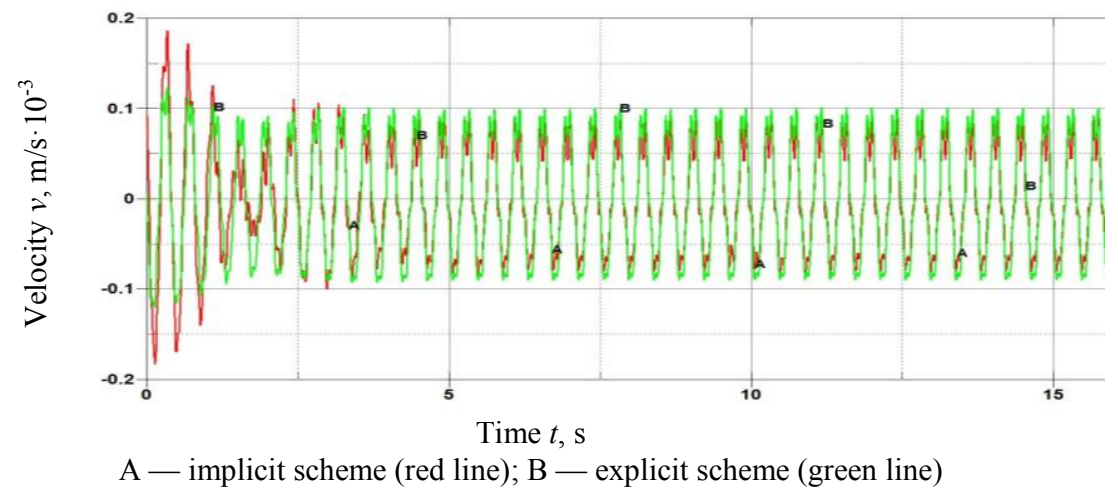

Fig. 5. Diagrams of a) acceleration and b) velocity at the grid point in the zone of steady vibrations.

The calculation for dynamic comfort $[5,7]$ is presented in the Table 2 .

Table 2. Dynamic comfort.

\begin{tabular}{|l|l|l|l|l|l|l|}
\hline $\begin{array}{l}\text { Geometric } \\
\text { mean } \\
\text { frequencies } \\
\text { of bands, } \mathrm{Hz}\end{array}$ & $\begin{array}{l}\text { Maximum } \\
\text { vibration } \\
\text { acceleration, } \\
\mathrm{m} / \mathrm{s}^{2}\end{array}$ & $\begin{array}{l}\text { Ultimate } \\
\text { vibration } \\
\text { acceleration, } \\
\mathrm{m} / \mathrm{s}^{2}\end{array}$ & $\begin{array}{l}\text { Factor of } \\
\text { dynamic } \\
\text { comfort }\end{array}$ & $\begin{array}{l}\text { Maximum } \\
\text { vibration } \\
\text { velocity } \\
\text { oct, } \mathrm{m} / \mathrm{s}\end{array} \quad \begin{array}{l}\text { Ultimate } \\
\text { vibration } \\
\text { velocity } 1 / 3 \\
\text { oct, } \mathrm{m} / \mathrm{s}\end{array}$ & $\begin{array}{l}\text { Factor } \\
\text { dynamic } \\
\text { comfort }\end{array}$ \\
\hline 2 & 2,9 & 10 & 3,45 & 0,1 & 0,79 & 7,90 \\
\hline 4 & 4 & 11 & 2,75 & 0,1 & 0,45 & 4,50 \\
\hline 8 & 4 & 14 & 3,50 & 0,1 & 0,28 & 2,80 \\
\hline 16 & 2,4 & 28 & 11,67 & 0,09 & 0,28 & 3,11 \\
\hline 31,5 & 17,3 & 56 & 3,24 & 0,07 & 0,28 & 4,00 \\
\hline 63 & 17,3 & 110 & 6,36 & 0,05 & 0,28 & 5,60 \\
\hline
\end{tabular}

Based on Table 2, we plotted diagrams of the factor of dynamic comfort in calculating the impact of pedestrian traffic (Figure 6).

a)

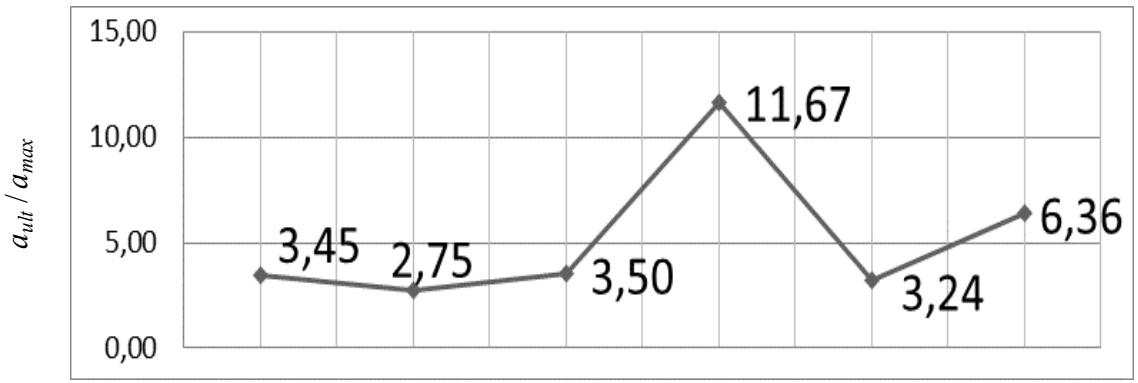

Geometric mean frequencies of bands, $\mathrm{Hz}$ 
b)

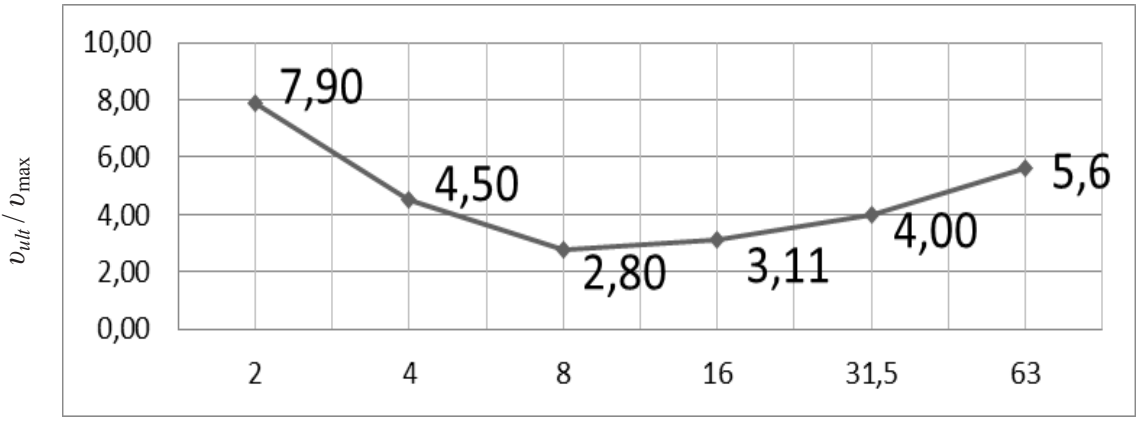

Geometric mean frequencies of bands, $\mathrm{Hz}$

Fig. 6. The diagrams of the factor of dynamic comfort in calculating the impact of pedestrian traffic by a) accelerations, and by b) velocity.

The results allow us to draw the following conclusions:

1) When the building is exposed to pedestrian traffic, the condition of dynamic comfort stands. The minimal factor equals to 2,75 at a frequency of $4 \mathrm{~Hz}$. Geometric mean frequencies ranging from $4 \mathrm{~Hz}$ to $31,5 \mathrm{~Hz}$ can be potentially dangerous;

2) The calculation for a gallery of the building regarding the impact of pedestrian traffic with explicit and implicit schemes of integration for motion equations gives a discrepancy in the results for vibration acceleration of up to 6 times. The values of vibration velocity are almost identical. The results differ in 1,1 times;

3) The design of buildings and structures for vibration by a direct dynamic method should include implicit schemes of integration for motion equations to avoid large errors in the calculated results.

\section{References}

1. Yu.P. Nazarov, V.N. Simbirkin, Journal CNIISK V.A. Kucherenko, 1, 10-18 (2009)

2. Yu.P. Nazarov, Yu.N. Zhuk, V.N. Simbirkin, A.V. Ananiev, V.V. Cournavin, Journal CNIISK V.A. Kucherenko, 2, 8-16 (2009)

3. ISO 10137, International Organization for Standardization (2007)

4. A.L. Smith, S. J. Hicks, P. J. Devine, SCI P354 (2007)

5. GOST R ISO 10137 -2016, Standartinform (2017)

6. European Commission - Technical Steel Research, RFCS Report EUR 21972 EN (2006)

7. $\mathrm{SN} 2.2 .4 / 2.1 .8 .566-96(1996)$ 